Article

\title{
Making Taste Public: Industrialized Orders of Sensing and the Democratic Potential of Experimental Eating
}

\author{
Jan-Peter Voß ${ }^{1, *}$ and Michael Guggenheim ${ }^{2}$ \\ ${ }^{1}$ Department of Sociology, Technische Universität Berlin, 10587 Berlin, Germany; E-Mail: jan-peter.voss@tu-berlin.de \\ 2 Department of Sociology, Goldsmiths, University of London, London, SE14 6NW, UK; E-Mail: m.guggenheim@gold.ac.uk \\ * Corresponding author
}

Submitted: 6 May 2019 | Accepted: 23 September 2019 | Published: 28 October 2019

\begin{abstract}
Existing discussions of food democracy focus on people's freedom to choose healthy, sustainable, or otherwise 'good' foods. Such foods are supposed to be unrestrained by oligopolistic structures of food supply, economic inequality, misinformation, or the misleading lobbying campaigns of the food industry. Our article aims to broaden the discussion about food democracy: focusing on people's freedom to choose the food they want, but also on people's freedom to engage with what they eat and how they want to eat it. This thematizes collective orders of sensing and, more specifically, taste. Based on pragmatist and praxeological studies we pose that tasting food is a matter of historically grown collective practices. In a second step, we assert that the reflexive shaping of such practices is currently dominated by the food industry and related forms of sensory science. Democratizing taste is a matter of people's capacity to self-govern how they experience and enjoy food. To this end, we suggest the approach of 'experimental eating' as a way to question and reflexively engage with embodied forms of tasting. We report on the development of methods that, in a next step, are to be combined for a participatory exhibition inviting people to experimentally reconfigure their habitual tasting practices and experience agency in matters of shaping taste. The exhibition makes taste public by demonstrating the construction of sensory experience in eating practices. It positions taste as a collective issue which every human being can experiment with-and thus to contest the governance of taste as currently exercised by industrial corporations and scientific experts.
\end{abstract}

\section{Keywords}

eating sociology; experimental eating; food democracy; food studies; sensory studies; taste

Issue

This article is part of the issue "New Perspectives on Food Democracy" edited by Basil Bornemann (University of Basel, Switzerland) and Sabine Weiland (Université Catholique de Lille, France).

(C) 2019 by the authors; licensee Cogitatio (Lisbon, Portugal). This article is licensed under a Creative Commons Attribution 4.0 International License (CC BY).

\section{Introduction: Towards Making Taste Public}

In 2005 Bruno Latour and Peter Weibel curated the exhibition "Making Things Public: Atmospheres of Democracy" (Latour \& Weibel, 2005). It comprised works of artists, scientists, sociologists, philosophers, and historians who were invited to explore questions of politics and representation. "Making Things Public" asked how conceptions and practices of democracy ought to include engagements with processes of thing-making. We allude to this attempt at widening the realm of politics and democracy. We also seek to include dimensions of col- lective life conventionally treated as natural, unchangeable, and therefore indisputable. 'Making taste public' contends that the constitution of taste is another dimension of collective ordering. As it stands the constitution of taste is reflexively shaped overwhelmingly by the food industry and its experts. 'Making taste public' suggests methods for how this can be shifted towards shared and public experimentation.

While "Making Things Public" demonstrated the ongoing construction of objects and their effects, 'making taste public' needed to demonstrate that people's ways of sensing, experiencing, and aesthetically judging are 
also continuously being constructed. Steven Shapin, in his presidential address to the Society of the Social Studies of Science in 2011 took up the same challenge. He suggested that one should challenge that the "modern sciences of subjectivity" embedded within "the aestheticindustrial complex" should "go on their way, largely unattended to by people like us" (Shapin, 2012, p. 179).

The historical construction of embodied sensory and aesthetic dispositions has long been known, for example, through Elias' and Bourdieu's studies of a culturally acquired habitus (Bourdieu, 1990, pp. 52-66; Elias, 1997a, pp. 76-82; Elias, 1997b, pp. 326-331). It is only fairly recently though that studies have shown the potential dynamics of ways of tasting (Hennion, 2004). For scholars such as Hennion, such ways of tasting are relationally constituted in practice, and may also reflexively be engaged with and experimentally shaped during the course of life. In Hennion's studies, such reflexive engagement with one's own ways of tasting can be observed in the experimental practices of dedicated amateurs. Other studies draw attention to the ways in which the food industry, supported by the sensory sciences, shape the collective orders of taste. As these practices aim towards creating standardized and globally saleable products, they tend to have a far broader reach and impact on the everyday practices of eating (Lahne, 2016, 2018). The resulting diagnosis is that taste is not unchangeably inscribed in our bodies, as if biologically evolved or as a habitus determined by social structure. As a practice, it can also be shaped reflexively. The actual capacities to do so, however, are unevenly distributed between corporate actors and consumers. This is the starting point for us to ask how the reflexive shaping of taste practices can be democratized. The line of inquiry presented in this article explores how the construction of taste can be demonstrated experientially and how people's capacities to engage with it can be nurtured so that they can challenge the dominance of industry and experts in these matters.

A key problem is that taste is not primarily articulated in discourse and material artefacts. It exists in embodied patterns of sensitivity, attention, affection, and experience. Turning taste political thus requires not only the deconstruction of stories and hacking of objects but also that one's own embodied ways of sensing is made amenable to reflexive engagement and contestation. Linguistic reflection, rhetoric, and argumentative reasoning, however, come to their limits when we turn to subjectivized and embodied rather than objectified orders of collective life. Autonomously and creatively engaging with collective orders of tasting is, first of all, a matter of stepping out of habituated ways of sensing (Hartmann, 2003). Acquiring critical capacities in matters of taste thus hinges on doing and experiencing, and on learning new ways of being attentive, new skills, and new techniques, rather than on symbolic (de-)construction, formal education or object-oriented expertise (Schwarz, 2013). It is here that democratizing taste fundamentally challenges conceived ways of understanding politics and democracy. This links up with a wider turn to performative, aesthetic, and affective dimensions of 'politics beyond words' (Butler, 2015; Dewey, 1934/2005; Marres \& Lezaun, 2011; Rancière, 2000/2013).

The Latin word sapere, defining us as homo sapiens sapiens and having fuelled the early modern democratization of state power with the slogan of "sapere aude!" (Kant, 1784/1963), not only means to know, in a figurative sense. It originally meant to taste, smell, find out differences and make a judgment. Instead of translating it as 'dare to think,' we could rather translate it as 'dare to sense.' Calling into question the primacy of consciousness, ideas and abstract reasoning after Plato, Descartes and Kant, it challenges us to bring sensory and aesthetic practice back into the public realm and to reinvigorate it as a capacity of collective sense-making (Rebentisch, 2012). Exploring food democracy may be an occasion to start from this other dimension of sapere.

We take some advice from precursors in feminist politics, specifically the seminal book Our Bodies, Ourselves, which focused on experimental sensing and affective expression as a medium of re-doing embodied constructions of selves (The Boston Women's Health Book Collective [BWHBC], 1973). This book and others enabled reflexive engagement with the ways in which maledominated medicine shaped perceptions of the female body. Seeking ways to democratize taste we follow the lead of these earlier attempts to renegotiate the sensing of one's body with the help of experimental methods. We look for methods not to educate people about the nefariousness of the food system, but to engage people in creatively exploring new ways of tasting or what we call methods of 'experimental eating.'

Such methods complement theoretical and empirical analyses of the dynamics of taste as a collective practice. They directly address the non-reflexive and embodied nature of tasting habits, by not only discursively questioning them, but by creating occasions for people to materially experiment with their own ways of tasting. These methods allow people to sense how their ways of tasting could be different, and to get an experience of being able to shape their ways of tasting. This is a precondition to ensure people do not simply subject themselves to established patterns of tasting (wherever they may have come from), but to subject these patterns to their own active interrogation, contestation, and engagement. We suggest, therefore 'experimental eating' as an approach for democratizing taste, and we will discuss preliminary steps towards developing it for deployment in a participatory exhibition set up in the course of a citizen science research project. This, we argue, is a necessary precondition for democratizing taste. It is a precondition for making taste public and for opening tasting up for contestation (for an extended discussion of pragmatist concepts of democracy see Butler, 2012; Dewey, 1927/2012; Latour, 2007; Marres, 2012).

We proceed by giving a brief overview of the state of research on taste as a collective practice in Section 2. 
We show that collective orders of tasting are dominantly shaped by business strategies, science, and governmental policy following an industrial logic. This leads us to ask in Section 3 how the shaping of how we collectively taste could be democratized. We face here the challenge of turning taste, and the ways in which it is being shaped, into an issue of public concern. This goes beyond discursive contestations with a view to the making of rules (by states) but has to work directly through the medium of sensory experience with a view to nurturing people's capacity to practically engage with their own ways of tasting. Building on such conceptual considerations we discuss in Section 4 the development of methods of experimental eating as components of a participatory exhibition to demonstrate, by means of sensory experience, how people can become agents in shaping their own ways of tasting. We conclude the article with a recapitulation of the challenge of deepening food democracy by opening up the dimension of taste, of how people sense food and how they want to eat, for wider public engagement by the people themselves.

\section{Tasting Like Industry and the Aesthetic Governance of Food Systems}

To understand the conditions of shaping taste and how it can be opened up for wider public engagement, we need to understand first how taste happens. How does a sensory experience come about as food meets the body? We base our considerations on recent social and anthropological studies of taste, which attend to the practices of sensory experiences. This leads beyond a conception of taste as the passive and individual perception of objective features of food, as proposed in psychological stimulusresponse models or phenomenological accounts of interpretive sense-making. Taste instead is evinced to be an active and collective way of doing sensory experiences (Counihan \& Højlund, 2018; Hennion, 2004; Sutton, 2010; Warde, 2008). It is then not something that one has, but something that one does, together with others-a pattern of movement someone participates in. This opens up the question of how such patterns emerge, if they are reflexively problematized and how, as well as whether attempts are made to shape them, by whom and with what effect.

As such, taste also becomes a potential political issue, a question of how collectives want to do tasteand a matter of questioning the democratic quality of how decisions are made that shape how collectives taste. Understanding taste as a practice thus opens taste up for inclusion in broader debates about food democracy, because it breaks with naturalized, individualized, or reified structural accounts of taste as an indisputable condition of life. In the following, we briefly recapitulate the basic premises of taste as practice and discuss how it allows us to account for the industrialization of food as it is experienced and desired.

Studies of taste as practice are part of a broader field of social studies focusing on practices as the constituting units of social life (Schatzki, Knorr-Cetina, \& von Savigny, 2001). Practices can generally be understood as patterned ways of doing something. They consist in relations of human bodies (with certain incorporated experiences, skills, and predilections), meanings (socially communicated knowledge, definitions, framings, norms, and values), and materialities (both designed artefacts and architecture as well as 'natural' materiality; Reckwitz, 2010, pp. 190-192; Shove, Pantzar, \& Watson, 2012). Compared to alternative accounts of social life, practice studies seek to decentre the intentional individual as a source of patterned social activities. Instead, practice theories acknowledge that practice is relationally constituted by heterogeneous elements. Recursive relations between elements such as human bodies, meanings, and materialities grant practices a life of their own. As dynamic compounds in themselves, practices recruit individual bodies into their processual logic and shape their subjectivities, including their cognitive and sensory dispositions.

The practice-oriented approach suggests that how we sense and experience is not a property of us as individual human beings or of the encompassing social structures, but that it is a property of specific practices in which we participate and train our bodies in specific ways. Other than in biological and psychological theories the senses are not assumed to work as fixed transmitters of information from the environment to the body (for an early critique see Dewey, 1896). Rather, sensing is actively practised in specific ways. It entails specific ways of being attentive and perceptive, letting oneself be affected, and making sense of affections (Hennion, 2004, 2015; Teil \& Hennion, 2004).

Turning from this general understanding of sensing as embedded in practices to the tasting of food as being embedded in practices of eating we recognize that it can be done in very different ways, depending on situational circumstances. Eating itself has been analysed as a "compound practice" usually linking up with other practices (Warde, 2013): Eating may occur in the context of daily life (as a rushed breakfast in the morning, a family meal at night, a snack on a journey), it may occur in the context of work, or it may occur in the context of a celebration, a religious ritual, a fitness programme, a medical treatment, etc. Specific ways of sensorially perceiving and evaluating food are integral to any of these varieties of eating and are shaped in relation to several other elements that make up these eating practices. As such tasting may happen in the background, with little intensity, serving instrumentally as a gatekeeper for accepting the intake of food in our bodies. But eating may also be done as a dedicated sensory practice, when the tasting of food moves into the foreground and when sensory perception and affection become the actual purpose of eating (Hennion, 2015; Reckwitz, 2016). This often happens in professional taste practices, but can also be observed in amateurs, for example, in the case of wine lovers who taste wine (Gomart \& Hennion, 1999; Teil \& Hennion, 2004). 
Historically, how we taste has evolved as has how we eat, which is connected with how we cook, produce food, and celebrate meals. All of this, of course, is embedded within regional, ethnic, religious, class, gender, and other patterns in which practices are clustered. However, a practice-oriented view refrains from reifying any of these patterns as structural determinants. It seeks to stay close to the actual doing and how it is constituted and changed by situationally specific constellations of its elements. Any specific configuration of taste can thus potentially become a matter of concern and reflexive engagement, opening it up for experimental exploration into how it could be done differently.

Understanding taste as practice positions people as agents with regard to how they taste. Yet, this is not what people in Western societies have been enculturated with. They learned to understand taste as both a bodily trait and an outcome of learning to eat the industrial foods on offer. Following Scott, we might call this 'tasting like industry' (Scott, 1998). Tasting like industry is guided by a basic interest in centrally governing eating practices, rather than allowing people to experiment with taste and food. The possibility of re-inventing and playfully shaping one's own ways of tasting is left out, as is getting together with others to collectively explore and articulate dissident ways of tasting. Tasting like industry has dominantly been shaped by the sensory sciences that emerged alongside the food industry (Lahne, 2016; Shapin, 2012; Spackman, 2018; Tracy, 2018; Ulloa, 2018). The food industry has approached taste with a view to determine and control it for epistemic as well as economic reasons. Guided by an interest in the general validity of knowledge claims and in the optimization of food products for large markets, science and industry approach taste with a framework to ascertain preferences as normal averages that are stable across situations. Industrialized taste in this sense has become performative (cf. Callon, 2007). It becomes enacted in the design and operation of consumer testing and marketing strategies. These, in turn, inform the configuration of products, packaging, retail environments, advertisement, dietary information and education materials, public discourses, policymaking, and regulations of how people interact with food.

Normalizing and passivizing people as tasters has enabled efficiency gains through industrialization and has become inscribed in the design of products and services through which people practically experience and learn to taste in their daily lives. More and more people learn to taste with food products optimized for industrial production and global marketing (Carolan, 2011/2016, pp. 1-7, 12-14, 16-42). Even seemingly non-processed foods such as milk (Atkins, 2016), vegetables, and fruits are industrially reprocessed, regulated, and standardized (Demortain, 2009; Frohlich, 2017). Alarming reports have highlighted that food corporations have attempted to strategically cultivate a way of tasting to make people crave ever more of their most profitable products, even baby food (Moss, 2013; Nestle, 2013; Schatzker, 2015). Contemporary consumers have been turned into a collective of "bodies tuned to fast food" (Carolan, $2011 / 2016$, p. 4) which, with time, have developed an "industrial palate" (van Esterik, 2018, p. 21). Conversely, public health campaigns typically fail when they call on consumers to heroically resist such a performative shaping of their tastes by abstaining from embodied eating habits.

This does not mean that industrial food practices do not also expand the taste experiences of modern consumers, by inventing new kinds of foods and making them ubiquitously available. But most of it happens within a specific ontology of taste as a matter of passive bodies reacting to objective qualities of food products. Even in less alarmist language, we can diagnose a path-dependency, and a locking-in to global industrialized foodways, not only in the dimensions of investments, technology, and institutions, which are usually looked at in studies of industrial transformation but also how people have come to know and do taste.

The industrial way of knowing taste is even further reified by public problem analyses and measures for education and governance which presume respective models of eating behaviour (cf. Schneider \& Ingram, 1990). Examples in this regard are health education programmes promoting dietary techniques for regulating bodily desire or ecological food policy controversies hung up on the question of how rigidly the state may, for matters of reason, rein in the pleasures of its citizens (Mol, 2009). Even counter-discourses and practices denouncing fast food and industrialized eating habits largely confirm the difficulty of changing tasting habits. They usually do not address taste, but seek to foster better ways of eating (slow, together, handmade, organic, regional, seasonal...). Such better ways of eating are then again addressed as a matter of education and individual responsibility for making conscious choices to regulate desires that are understood as given (Biltekoff, 2013; Guthman, 2011). What is cultivated in all these instances is a way of understanding and practising taste that is deeply aligned with industrial methods of food production and marketing which rely on knowing objectively, universally, and predictably what people like and what they want.

This way of shaping taste by enacting it as indisputable subdues the agency of people in shaping it and brackets taste out from politics and contestations of the governance of food systems. It must, therefore, be regarded as a fundamental form of power. It is a power at work along with the power of market shares, production empires, property and financial resources, favourable laws and promoting institutions or supporting discourses of food security and efficiency. It is a power resting in fixing what people want to the given ways in which their bodies desire. This is what we may call the aesthetic governance of food systems.

In these ways, the industrial mode of managing food systems narrows down pathways of development, possi- 
bilities for mobilization and transformation. It is very difficult to convince people to eat foods they do not like. Examples here are the challenge of establishing insects as a sustainable protein source or development aid workers trying to 'help' people with foods that fall outside their taste preferences. This is also true the other way round: It is very difficult to prohibit food that people do like, see for example the failure of prohibition laws, the campaigning disaster of the Green Party in Germany announcing a veggie day, or the fights around unpasteurized cheese (Paxson, 2010).

Just as the successes of industrial modernization are tied up with specific enacted ontologies of tasting, so are their repercussions. Responding to them, therefore, requires engagement with how we know and do taste. Democratizing taste then means questioning the genesis of learned ways of appreciating, enjoying, or being disgusted by food. Democratizing taste means devising methods to work against the naturalization and reification of taste and to question existing ways of tasting like industry. It suggests equipping people with the means to explore and develop alternative ways of sensing food. Learning to taste differently is a political practice because it practically contests the dominant ways how collective patterns of tasting are being shaped. This is a precondition for taste to become a public issue and an arena of more people-led negotiations of collectively practised aesthetic orders.

\section{From Acknowledging Aesthetic Governance to Democratizing Taste}

How can we engage with ways of knowing and doing taste in the context of current industrialized food systems? How can we redress the dominance of production and marketing interests in the aesthetic governance of food systems? How can we open up the shaping of collective taste practices for a broader and more inclusive engagement with the public? These are key questions for overcoming aesthetic path dependency and enabling innovation in food systems, but they can also be framed politically, as key questions for democratizing the aesthetic governance of food systems. They aim to open up the shaping of taste practices for more inclusive engagement with the people who perform them. In the following, we discuss how these questions can be taken up in concrete activities for democratizing taste.

A pivotal step is to de-naturalize tasting habits by demonstrating and experiencing how tasting could be otherwise. This breaks with understanding taste as structurally given, only to be decrypted by science, and impossible to shape, because this understanding effectively shields the shaping of tasting practices from equal engagement and public problematization. To democratize taste, we thus need a different way of knowing taste.

For taste to become amenable to democratic engagement, it must be conceptualized in a way that does not position citizens as either biological or cultural dopes who simply execute structurally determined sensory dispositions and desires. Rather, citizens should be considered to have reflexivity, discretion, and agency in matters of their own tasting. This shift is very different from critiquing established taste practices as false or underdeveloped and heralding an improvement in tasting, in the sense of making individuals more discerning. This would merely amount to a strategic reverse engineering of Bourdieu's habitus concept. Rather, democratizing taste requires people to be aware of what happens when they taste and be capable to act on it. Only then will they engage with the politics of taste on their own terms, rather than the terms of some expert's political project.

The previously reviewed sociology of the senses already points towards a democratization of taste by such a break with established ways of knowing taste. This literature provides alternative ontological and theoretical frames, research designs, and methods. These make visible and enact a different reality of tasting as potentially diverse, dynamic, and shaped by eaters who reflexively and collectively develop their own ways of tasting. As discursive and conceptual work such new ways of doing research on taste are key to the democratization of taste. Yet, there is still a gap to be bridged between observing and theorizing how people may taste differently in certain settings and enabling people to actually taste differently. It is a performative inconsistency of the literature on sensory sociology that its main output is a theoretical text or an empirical description. As a text, it operates in a mode that practice-oriented studies analyse for its shortcomings in capturing social life as it unfolds. It implies that readers would change their habits by cognitively understanding the argument of the text and based on this cognitive understanding being subsequently willing and able to autonomously modulate their sensing practices and ultimately their bodily dispositions. But practice theory, in sync with public health, has shown that this is precisely not how humans work. People do not start eating worms and crickets because they have been told that they could learn to enjoy them.

To overcome this performative shortcoming and to actualize the potential agency that recent studies of taste attribute to people, the challenge thus is to look out for approaches of knowing and doing taste differently that are themselves practical, bodily, affective, and sensory. Unleashing alternative forms of knowing taste in practice thus appears as an approach which deserves to be explored. Before we get there, however, we discuss how not only taste needs to be understood in different ways to open it up for democratic engagement, but also how our understanding of democracy has to move away from conventional modern ways of knowing democracy in terms of state government, party competition, elections, parliamentary debate, open and transparent stakeholder negotiations, and occasional referenda (e.g., Held, 1987/2006).

The main point here is to go beyond discourse and institutions as the medium within which governance, 
politics, and, correspondingly, democracy is thought to play out. Traditionally the knowing and doing of governance has focused on the making of formal and informal rules. Institutions, norms, and laws have been foregrounded as relevant dimensions of collective ordering that were to be reflected, problematized, and collectively shaped in contestations over how they could best serve the public good. Since the 1970s the "cultural turn" has contested how we conceive of collective ordering processes (Bachmann-Medick, 2011; Nash, 2001). The cultural turn shifted attention to deeper dimensions of collective ordering beyond explicit ruling and political debate. It brought into view the implicit world orders, the ontologies that are enacted as collectively binding in the ways in which normal life is performed: Some research has focused on the use of language and the practicing of certain forms of rationality (Governmentality Studies, e.g., Foucault), some on scientific knowledge production and the design of technology (Science and Technology Studies, e.g., Latour), and others on gender relations and the construction of embodied subjectivities (Gender Studies, e.g., Butler). Against this background, the doing of politics and governance could no longer be restricted to rule-making in or beyond the state. Rather, it had to include processes which shape the very categories with which we communicate and think, the methods by which we observe and structure reality, and the ways in which we comport our bodies and our senses. This conceptual broadening of analytical perspectives on governance and politics has continued to problematize the collective ordering taking place in practices of sensory perception, affect, and creativity (Howes, 2005; Rancière, 2000/2013; Reckwitz, 2012/2018; Voß, Rigamonti, Suarez, \& Watson, 2018).

This cultural turn has been accompanied by a wave of activist projects and movements that have begun to question the power relations embedded in everyday and professional practices. In the 1970s and 1980s, people started to develop practices of lay experimentation in order to challenge received expertise. These practices emerged in a variety of fields such as science shops, community arts and architectural self-build movements, as well as feminist body and health practices (Guggenheim, 2010). The latter, in particular, provide a relevant precedent for our interest in the democratization of embodied sensory orders.

Our analysis above has pointed to the ways in which tasting itself as a bodily practice has been shaped by the food industry. It is a fundamental bodily function which people assume to be normal without considering that it has been shaped by specific industries. The history of feminist body practices can give us insight into precursors of how to understand and unlearn similar ways that bodies have been taken for granted. In the case of feminist body practices attention was obviously not focused on food and taste, but on the ways that a male-dominated medicine conceived of the female body. Women began to understand that how they understood their bodies was framed by medical discourse and practices. Women began to claim that the medical profession, at that point overwhelmingly male, gave accounts of their bodies that they found wrong and harmful. But to understand the ways in which these accounts of and practices with female bodies were wrong, it was not enough to simply read and write against them. Rather, it required women to unlearn and re-learn their own bodies in action.

The publication of a course manual Our Bodies, Ourselves in 1971 defined a new way of writing, understanding, and experiencing the body (BWHBC, 1973). It was translated in many languages and sold millions of copies. Our Bodies, Ourselves was unusual, because it sought to challenge the medical authority over women's bodies not just by replacing received medical knowledge with other knowledge, but by encouraging a new, democratic, experimentalized and political relationship to bodies. A complex recursive relationship was already present in the writing, where the writers were a collective that wrote about their own bodies. The book itself was based on close observation and comparison of the authors' bodies. But at the same time, these authorship practices extended to the readers: "readers were addressed as 'we,' encouraged to identify with personal narratives, and invited to use the book as a prop for exploration of their own bodies" (Wells, 2010, p. 11). As Michelle Murphy explains, the invitation to experiment with bodies created a form of "affective entanglements":

A moral economy of affirmation-of the happiness of knowing oneself through bonding and of recognition of oneself in others as a politicizable collectivity. At the same time, objectivity was reassembled as a project of self-knowing only possible in politically and affectively charged relations with other subjects. (Murphy, 2012, p. 90)

Importantly, there is a connection here between selfexperimentation as a new way to explore one's body, and knowing that such self-experimentation leads to the formation of new collectives.

There are obvious links here with how we conceptualize the challenge of democratizing taste. Focusing on taste, however, broadens the scope of engagement from the body itself to situations in which the body encounters food, and in which we eat and taste. This also implies that experimental explorations require engaging with the complex interplay of one's own body, a multiplicity of highly diverse food items and their relational embedding in specific eating situations (where, when, with whom, in which atmosphere, which furniture, utensils, etc.). Democratizing taste then is not merely a matter of experimenting with one's own body, but about reorganizing the situations in which eating and tasting happens (see Derschmitt, 2017, for an example of how to experimentally politicize eating situations with public "permanent breakfasts"). 
Some approaches of food politics, like the one pursued in the Slow Food movement, already take steps in this direction by arranging workshops and meetings which allow participants to explore and learn attentive and conscientious ways of eating and tasting (Panagia, 2010, pp. 123-148). They engage with food systems as sensory orders and practice a sensory mode of political mobilization by affectively attracting interest and collective identification. With regard to the democratization of taste, however, they fall short when compared with the women's collective 'Our Bodies, Ourselves' and the later gender studies and queer movement in the ways in which they opened up embodied cultural assumptions. By focusing on pleasure and responsibility without questioning culturally constructed taste as a framework for experiencing pleasure the Slow Food movement is, like early feminist struggles for women rights, limited in its effectiveness to what is possible within the historically established sensory order. There is also a reflexive debate emerging, however, with regard to the relative conformism of the movement and how it reifies established taste patterns of white middle-class aficionados as good taste (Hayes-Conroy \& Martin, 2010). Thus, instead of fighting for a specific taste we suggest moving to the queering of taste by experimentally opening up the practical and embodied ways in which people collectively experience taste.

We have started to work on methods of 'experimental eating.' Such methods create an occasion and provide a setting for stepping out of habitual ways of eating and tasting and invite people to explore new and different ways of eating. The basic approach for methodically triggering experimentation is to withdraw or exchange constitutive elements of the usual way of doing eating and tasting. We begin by disassembling established practices (Roehl, 2012, pp. 118-119) or by disrupting typical practice (Garfinkel, 1967). This is achieved, for example, by requiring that eating is done with the fingers, after some physical exercise, alone or under observation, or eating as if one knew that the food was poisonous or from most expensive delicatessen, as if one were a giant or a rabbit, or by eating a meal composed of ingredients that have randomly been brought to the table. In any case, it is left up to the people who use the method to reassemble the situation by re-relating other elements with the deliberately altered element so as to find a way of doing taste under these changed circumstances. It is here that experimentation comes into play. Because people cannot rely on their habits anymore, they invent their own ways of tasting. Experimental eating methods thus make people become creative agents in matters of doing taste. They make them experience how it feels to be a creative agent who invents and explores other potential ways of tasting.

We are currently developing such methods in a citizen science research project, together with a diverse set of twenty interested amateur researchers and with expertise mobilised from a variety of academic disciplines and arts (Schmeck!, n.d.). The further aim is to arrange a participatory exhibition with a parcours of about ten stations. At each of them, a different component of established eating practices is experimented with. Over the course of the parcours, each participant explores experiential effects that arise from shifting and modulating components of their eating practices across the dimensions of the body, meaning, and materiality. In the end, participants eat a self-made meal in a self-defined situation, exploring how it shapes their sensing and tasting. They thus experience how reassembling and reinventing taste works, that it is possible, perhaps fun, and maybe even delicious. While such exercises in experimental eating are research, providing insights on how ways of tasting can change, they are also political interventions for democratizing taste. In the next section, we give more detail on the design of such methods and how they work.

\section{Devising Methods for Experimental Eating and Tasting}

A number of pre-tests with methods of experimental eating have been carried out. The first by Michael Guggenheim at the launch of a special issue on "The Raw and the Cooked" of the cultural studies and science and technology studies (STS) magazine Avenue (Avenue, n.d.), followed by Michael Guggenheim and Laura Cuch at the European Association for the Study of Science and Technology (EASST) 2018 conference in Lancaster (Guggenheim \& Cuch, 2018) and finally by Jan-Peter Voß and Daniel Kofahl with participants of the Sensing Collectives workshop held in the autumn 2018 in Berlin (Voß, Rigamonti, Suarez, \& Watson, 2018). The details of the report below are based on the second of these events. The pre-tests were carried out with academics (at EASST and Sensing Collectives) and readers of a cultural studies/STS/history magazine in the case of Avenue. In each case, the participants self-selected by answering calls for each event. What is relevant is not so much the outcome of the specific experiments, but the logic and feasibility of the experiments as testing grounds for setting up a public exhibition for wider participation in reassembling taste.

The goal of these pre-tests was twofold. The first goal was to trial various experimental methods that each address a different element of eating practices in how they affect taste, such as political or religious framings, different knowledge of ingredients, or different kinds of utensils. The second goal was to explore the sequencing of such methods as a way to create new dishes. With this latter goal, we relate to the diagnosis that many people have lost experiential knowledge of how tasting results from the composition of ingredients, bodies, mindsets, tools, and atmospheres-and how it can be shaped by tinkering with different components (e.g., Carolan, 2011/2016; Flammang, 2009). Abstract advice to 'enjoy eating' or 'eat healthier' would thus need to be complemented by practical experience of how it can be done and what it does. The goal of this sequencing was to 
make people understand that eating situations comprise more than dishes and meals and that they can be de- and re-assembled in search of new taste practices.

In each case of our pre-tests with experimental eating, with slight variations, participants were given a sequence of exercises and experiments that led to the construction of a dish. Participants were asked to bring two random ingredients. They then shared them with four other people at their table, so that each had six ingredients in front of them. The randomizing of ingredients demonstrated that it is the cook's logic and creativity that creates a dish, rather than preconceived logic of what goes with what. It laid the basis for giving the participants the powers to design a dish from constituent taste experiments. They were then asked to select random ingredients for each other, blind taste each ingredient and take notes of the tasting experience. Each ingredient had to be tasted differently. The note taking was a crucial element, as it forced the participants to reflect on the tasting experience. The first ingredient was simply tasted as is. This served as a benchmark for the following tasting experiments. The second was tasted as if it were something else, say an apple (this is based on the Fluxus artist and folklorist Bengt af Klintberg's event score No. 8; Klintberg, 1967, p. 7). It highlighted the idea that tasting as a social practice is informed by pre-existing bodily practices and expectations of how we eat what. The further tastings were sociological variations of this event score: The third was tasted as if the taster were a mouse or some other animal. This moved the focus away from the tasted object to the body of the taster. The fourth was tasted as if the ingredient had no nutritional value. The fifth was tasted as if it were a divine gift, and the last as if it were dangerous, infected by a parasite. These latter two focused on how cultural meanings of food products inform the way we eat and taste.

After having tasted each ingredient, participants were instructed to build a dish out of these ingredients according to at least one guiding socio-logic, such as Gender, Ecology, Politics, Health, Humans/Non-Humans, Technology, or Religion. That is, they had to define a logic which would structure how ingredients relate to each other and which quality of each ingredient they would make relevant (taste, colour, social meaning etc.). They were asked to construct a story that connects the different ingredients and at the same time arrange the ingredients, their tastes, meanings and qualities into a dish. Each participant had also been asked to bring an eating utensil (a knife, fork, plate, piece of plastic or wood that would serve as either plate or cutlery) and to explain how this utensil fits into the logic of the dish.

Participants in the exercise had various tools at their disposal to prepare, cut, slice, arrange, and measure the ingredients. Finally, they were asked to define a consumption situation (where, when, how?) that would suit the dish. Through all these steps they were induced to move from the taste experiences in the first part to compositional logic. They were encouraged to invent a dish based on their taste experiences. To eat, they were asked to share their dish with their neighbour and explain the logic of the dish. Thus, each person at the table would create a different dish, enabling different tasting experiences and enacting different socio-logics from the same set of ingredients.

From this short explanation, the following elements of each of these exercises become apparent: Each exercise sensitized the participants to the food they were eating. The sensitization happened because an arrangement was created that slowed them down and directed attention to their own bodily experiences. This was first prompted by participants being required to take notes for each tasting. We prepared a notation sheet, which encouraged each participant to record their results and thoughts. Second, the heightened attention came from enticing participants to taste in ways they would normally not taste. In this sense, the tasting experiments were a kind of breaching experiment (Garfinkel, 1967; for a similar translation of breaching into design see Stuedahl \& Lowe, 2013). Harold Garfinkel invented breaching experiments as a way to demonstrate unwritten rules of ordinary interactions by disturbing these interactions without announcing this to the participants beforehand. For example, he would send students home and asked them to pretend not to know their parents or he would point out during interactions with strangers that he was recording the interaction. In each case, the startled reactions would demonstrate the underlying rules of interactions and the repair work people engage in to rectify the situation. Other than Garfinkel's breaching experiments, our experiments were not (cruel) acts to which others were unwittingly exposed, but shared experiences collectively undertaken in order to demonstrate what happens in ordinary taste practices and to create new taste experiences. The breaches were bodily and practical, as the tasting was not merely a breaching of normative expectations and cognitive routines, but of practical, bodily and sensory ways of relating with food, how to eat and how to experience eating.

For example, tasting an ingredient as if it were divine makes the taster attentive to how social meanings, which are often latent, form the practice of tasting. People experience that ingredients are never just ingredients; their taste is imbued with social expectations and consumption contexts. Tasting an ingredient as if one were a rabbit makes the taster aware of their own body and how it helps constitute what they eat. While we cannot become rabbits, eating as a rabbit forces us to change the way we practically eat, which in turn changes how we taste. These are just a few examples of how such exercises stimulate the development of new eating and tasting practices and indeed differently bodily and sensory experiences of food.

The experiments also made taste an issue of collective attention, communication, and negotiation. They made taste public, even if initially only on a limited scale. In every step, the doing of taste and the experience it 
created did not remain individual but had to be shared. Strangeness, novelty, and surprise became a matter that could be discussed. Participants were invited to talk and write, but also watch and listen to how others go about tasting. Within the group of experimentators tasting thus became an issue of public deliberation, of judgment and exchange.

Importantly, these novel experiences of eating and tasting could not simply be attributed to the organizers of the experiments, because every single dish was mediated through each participant's own way of doing each exercise. The participants created and owned their own dish. They were the cooks, the choreographers, and the tasters, the sociological analyst and eaters folded in one. They were those who conducted an inquiry into their own taste and a more collective understanding of how tastes come to be and how novel tastes can form.

These pre-tests are first attempts at materializing conceptual considerations of the democratization of taste. They serve to illustrate the general approach of experimental eating with concrete examples of how methods could be devised that can make people experience themselves as agents in matters of tasting. In our current work, we set out to build on and develop this approach into a set of methods to be systematically combined to provide a parcours for a participatory public exhibition of tasting practices. Conceptually, we think about a set of methods to experimentalize tasting and eating in its various constitutive aspects, broadening out from a focus on the cooking of dishes to the composition of situations. Linking up with practice-oriented studies of tasting we seek to devise methods systematically addressing constitutive components in the dimensions of bodily dispositions, meanings, and materiality. The goal is to compose a set of methods that create a parcours which, by passing through them one by one, would allow taste to be sequentially unravelled and recomposed as embedded in specific situational arrangements of eating. It would induce people to experience the construction of taste from its various components. It would offer each of these components as a starting point for opening up, experimentally exploring possibilities, inventing new ways of tasting and thus, eventually, engaging with the ongoing shaping of collective orders of tasting. The development of such a set of methods is itself a matter for experimentation which we are carrying out together with a wider group of amateur researchers and disciplinary experts in the context of a citizen science research project. In upcoming publications, we will be able to describe the specific set up of the exhibition and report on how it was adopted by

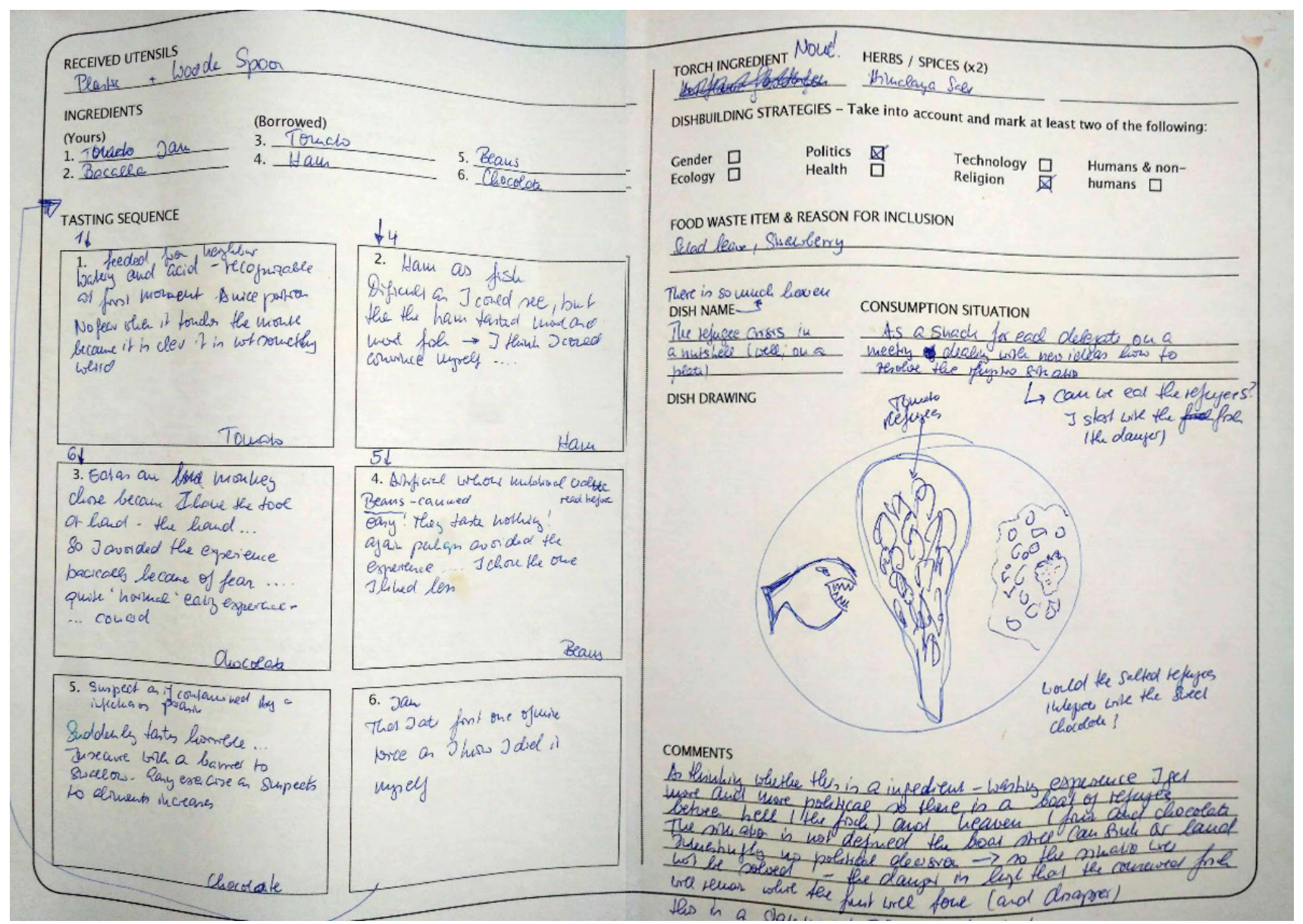

Figure 1. Participant's notes from a pre-test with experimental eating methods at EASST 2018 in Lancaster. Source: Michael Guggenheim. 
a broader public, and to what effect with regard to sensorially opening up eating and making taste a public issue.

\section{Conclusion: The Challenge of Democratizing Taste}

We began this article by arguing that taste matters when it comes to democracy. That is, to understand the governance of food systems, we also need to understand and intervene in the ways people have learned to taste. The ways in which collective taste has historically taken shape, however, are clearly dominated by interests in industrially optimizing and controlling the production and consumption of food. Diagnosing the aesthetic governance of food systems highlights that it is corporate agency, not citizens, that has power. How people taste is widely understood as being structurally given and unchangeable and therefore not worthy of debate. Appetite and desire, or aversion and disgust can at most be tamed and regulated. Collective patterns of tasting are key stabilizers of an industrial path of food system development, alongside more frequently analysed politicaleconomic, institutional, technological, or epistemic patterns. Here is an important additional dimension where "profit-oriented multinational corporations as well as international networks of scientific and administrative experts...are making critical decisions regarding the food system" (Bornemann \& Weiland, 2019, p. 2). We could add that these companies and experts also make critical decisions about how food is collectively tasted and enjoyed or dismissed. We thus suggest that we should shift the discussion about food democracy, from a focus on the freedom of the people to choose the food they want, to the freedom of the people to engage with what and how they want to eat.

The current way of knowing taste effectively prevents this from becoming a public issue. It prevents taste from becoming politicized that is, from contesting the question of 'how do we want to taste?' As long as taste is understood as determined by biological or social structures, something people have, rather than something people do in certain ways and via interaction with others, it is effectively shielded from contestation and the articulation of alternatives.

At the start of this article, we alluded to "sapere aude!" (Kant, 1784/1963) as a slogan for the enlightenment movement. Kant introduced it as a response to his diagnosis that people would follow interpretations of the world established by authorities rather than daring to think on their own, thus remaining captured in self-imposed immaturity. We can take issue with how he charges citizens with laziness and timidity, thereby individualizing the responsibility for their subjection. Yet, in subsequent years it became an opener for the articulation of contesting views and the rise of public debate about how collective life should be governed. This ultimately led to a gradual democratization of governance by formal rule-making. In tune with the original Latin meaning of sapere in 'sapere aude!' the enlightenment movement, however, by focusing on words and thinking, liberated people from self-imposed immaturity only regarding a limited part of their existence. But sapere originally meant to taste, and then, more broadly referred to a capacity to make differences and judgments. If we relate this to how people currently do taste seemingly by expertly deciphered irreversible biological and social imprints, then it would seem that we are still in a preenlightened, pre-democratic state of self-imposed immaturity. Food democracy is unlikely to come into being under such circumstances.

It was a key issue for the enlightenment movement to argue that the subjection under existing orders is not required by destiny, divine will, or the natural orders of class, sex, or race. In the same way, it is a key issue for democratizing taste to demonstrate and make sensible how subjection under existing orders of taste is not a given. These orders can be engaged with by exploring our own ways of sensing.

Recent anthropology and sociology of sensing and taste provide a conceptual starting point. We can learn that the ways in which human beings sense is not universal and naturally given, but is historically shaped in interactions and resides in collective practices rather than individual organisms. Perception, affect, and taste thus come into view as another dimension of collective ordering and as another medium of politics and governance. So far, however, this comes into view only through the classical enlightenment path of thinking. What we identified as a challenge for democratizing taste is to avoid believing that sociology as a purely cognitive critique will affect tasting practices. We know from both empirical studies and the insights of practice theory that abstract knowledge does not easily translate into practice. People do not stop eating unhealthy food, even though they know from public health campaigns that it is unhealthy. Rather, we suggest exploring more comprehensive capacities of sense-making to help people realize agency in matters of taste. This is a key challenge for democratizing taste. Working towards the democratization of factmaking by making things public was effective within the visual and textual environment of an exhibition accompanied by a catalogue. If we conceptualize knowing as embodied and resting in practices, then making taste public poses the challenge that we have to engage with these bodily practices themselves.

We need to focus on the ways in which we can collectively find new ways of tasting. The approach of experimental eating which we have outlined and illustrated by reporting these pre-tests is a concrete attempt at articulating food democracy in practice. By this we move from analysis, stating that tasting is cultural and currently dominated by industrial food production and science, to finding ways of opening up collective orders of tasting for engagement by those who live them. If taste itself is to become a matter of democracy, we need to think about appropriate methods that allow us to develop capacities to intervene in the collective formation of taste. 


\section{Acknowledgments}

Research for this article has been carried out as part of the project "Schmeck! Aesthetics and Practices of Eating in the Context of the Sustainable Transformation of Food Systems: A Pilot Project in Qualitative-Sensory Citizen Science" (www.schmeckprojekt.de). We are grateful to our professional and amateur colleagues in the Schmeck! Project for stimulating discussions and sensory experiences which have informed the writing of this article. We acknowledge financial support by the Presidency of Technische Universität Berlin through its strategic funding initiative for Citizen Science and by the German Research Foundation and the Open Access Publication Fund of TU Berlin. Thanks also to three anonymous reviewers and editors of this thematic issue for excellent critique and suggestions in response to a first version of this article.

\section{Conflict of Interests}

The authors declare no conflict of interests.

\section{References}

Atkins, P. (2016). Liquid materialities: A history of milk, science and the law. London: Routledge.

Avenue. (n.d.). Roh \& gekocht. Avenue. Retrieved from https://avenue.jetzt/category/roh_gekocht

Bachmann-Medick, D. (2011). Cultural turns: Neuorientierungen in den Kulturwissenschaften [Cultural turns: New orientations in the study of culture]. Hamburg: Rowohlt Verlag $\mathrm{GmbH}$.

Biltekoff, C. (2013). Eating right in America: The cultural politics of food and health. Durham, NC: Duke University Press.

Bornemann, B., \& Weiland, S. (2019). Editorial: New perspectives on food democracy. Politics and Governance, 7(4), 1-7.

Bourdieu, P. (1990). The logic of practice. Stanford, CA: Stanford University Press.

Butler, B. E. (Ed.). (2012). Democratic experimentalism. Amsterdam: Edition Rodopi.

Butler, J. (2015). Notes toward a performative theory of assembly. Cambridge, MA: Harvard University Press.

Callon, M. (2007). What does it mean to say that economics is performative? In D. MacKenzie, F. Muniesa, \& L. Siu (Eds.), Do economists make markets? On the performativity of economics (pp. 311-357). Princeton, NJ: Princeton University Press.

Carolan, M. S. (2016). Embodied food politics. London: Routledge. (Original work published 2011)

Counihan, C., \& Højlund, S. (2018). Making taste public: Ethnographies of food and the senses. London: Bloomsbury.

Demortain, D. (2009). Legitimation by standards: Transnational experts, the European Commission and regulation of novel foods. Sociologie $d u$
Travail, 51, e104-e116. https://doi.org/10.1016/ j.soctra.2009.06.022

Derschmitt, F. (2017). Permanent breakfast: The main idea. Permanent breakfast. Retrieved from https:// www.permanentbreakfast.org

Dewey, J. (1896). The reflex arc concept in psychology. Psychological Review, 3(4), 357-370.

Dewey, J. (2005). Art as experience. New York, NY: Penguin. (Original work published 1934)

Dewey, J. (2012). The public and its problems: An essay in political inquiry. University Park, PA: Penn State Press. (Original work published 1927)

Elias, N. (1997a). Über den Prozess der Zivilisation [On the process of civilization] (Vol. 1). Frankfurt am Main: Suhrkamp.

Elias, N. (1997b). Über den Prozess der Zivilisation [On the process of civilization] (Vol. 2). Frankfurt am Main: Suhrkamp.

Flammang, J. A. (2009). The taste for civilization: Food, politics, and civil society. Chamapign, IL: University of Illinois Press.

Frohlich, X. (2017). The informational turn in food politics: The US FDA's nutrition label as information infrastructure. Social Studies of Science, 47(2), 145-171.

Garfinkel, H. (1967). Studies of the routine grounds of everyday activities. In H. Garfinkel (Ed.), Studies in ethnomethodology. (pp. 35-75). Englewood Cliffs, NJ: Prentice-Hall.

Gomart, E., \& Hennion, A. (1999). A sociology of attachment: Music amateurs, drug users. The Sociological Review, 47(S1), 220-247.

Guggenheim, M. (2010). The long history of prototypes. Limn, 2010. Retrieved from https://escholarship.org/ uc/item/7v60990z

Guggenheim, M., \& Cuch, L. (2018). Encounter, create and eat the world: A meal (workshop). EASST Review, 37(4). Retrieved from https://easst.net/ article/encounter-create-and-eat-the-world-a-mealworkshop

Guthman, J. (2011). Weighing in: Obesity, food justice, and the limits of capitalism. Oakland, CA: University of California Press.

Hartmann, M. (2003). Die Kreativität der Gewohnheit: Grundzüge einer pragmatistischen Demokratietheorie [The creativity of habit: Basics of a pragmatist theory of democracy]. Frankfurt am Main: Campus.

Hayes-Conroy, A., \& Martin, D. G. (2010). Mobilising bodies: Visceral identification in the Slow Food movement. Transactions of the Institute of British Geographers, 35(2), 269-281.

Held, D. (2006). Models of democracy. Standord, CA: Stanford University Press. (Original work published 1987)

Hennion, A. (2004). Pragmatics of taste. In M. D. Jacobs \& N. Weiss Hanrahan (Eds.), The Blackwell companion to the sociology of culture (pp. 131-144). Malden, MA: Blackwell Publishing. 
Hennion, A. (2015). Paying attention: What is tasting wine about? In A. Barthoin Antal, M. Hutter, \& D. Start (Eds.), Moments of valuation: Exploring sites of dissonance (pp. 37-56). Oxford: Oxford University Press.

Howes, D. (2005). Empire of the senses. Oxford: Berg Publishers.

Kant, I. (1963). An answer to the question: What is enlightenment? London: Penguin. (Original work published 1784)

Klintberg, B. a. (1967). The cursive Scandinavian salve. New York, NY: Something Else Press.

Lahne, J. (2016). Sensory science, the food industry, and the objectification of taste. Anthropology of Food, 2016(10). Retrieved from https://journals. openedition.org/aof/7956

Lahne, J. (2018). Standard sensations: The production of objective experience from industrial technique. The Senses and Society, 13(1), 6-18.

Latour, B. (2007). Turning around politics: A note on Gerard de Vries' paper. Social Studies of Science, 37(5), 811-820.

Latour, B., \& Weibel, P. (Eds.). (2005). Making things public: Atmospheres of democracy. Catalogue to the show at Zentrum für kulturelle Kommunikation, Karlsruhe. Cambridge, MA: MIT Press.

Marres, N. (2012). Material participation: Technology, the environment and everyday publics. Basingstoke: Palgrave Macmillan.

Marres, N., \& Lezaun, J. (2011). Materials and devices of the public: An introduction. Economy and Society, 40(4), 489-509.

Mol, A. (2009). Good taste: The embodied normativity of the consumer-citizen. Journal of Cultural Economy, 2(3), 269-283.

Moss, M. (2013). Salt, sugar, fat: How the food giants hooked us. New York, NY: Random House.

Murphy, M. (2012). Seizing the means of reproduction: Entanglements of feminism, health, and technoscience. Durham, NC: Duke University Press.

Nash, K. (2001). The 'cultural turn' in social theory: Towards a theory of cultural politics. Sociology, 35(1), 77-92.

Nestle, M. (2013). Food politics: How the food industry influences nutrition and health. Oakland, CA: University of California Press.

Panagia, D. (2010). The political life of sensation. Durham, NC: Duke University Press.

Paxson, H. (2010). Cheese cultures: Transforming American tastes and traditions. Gastronomica, 10(4), 35-47.

Rancière, J. (2013). The politics of aesthetics. The distribution of the sensible. London: Bloomsbury. (Original work published 2000)

Rebentisch, J. (2012). Die Kunst der Freiheit: Zur Dialektik demokratischer Existenz [The art of freedom: On the dialectics of democratic existence]. Frankfurt am Main: Suhrkamp Verlag.
Reckwitz, A. (2010). Auf dem Weg zu einer kultursoziologischen Analytik zwischen Praxeologie und Poststrukturalismus [Towards a culture-sociological analytics between praxeology and post-structuralism]. In M. Wohlrad-Sahr (Ed.), Kultursoziologie [Sociology of culture] (pp. 179-205). Wiesbaden: SpringerVS.

Reckwitz, A. (2016). How the senses organise the social. In M. Jonas \& B. Littig (Eds.), Praxeological political analysis (pp. 68-78). London: Routledge.

Reckwitz, A. (2018). The invention of creativity: Modern society and the culture of the new. Boston, MA: John Wiley \& Sons. (Original work published 2012)

Roehl, T. (2012). Disassembling the classroom-An ethnographic approach to the materiality of education. Ethnography and Education, 7(1), 109-126.

Schatzker, M. (2015). The dorito effect: The surprising new truth about food and flavor. New York, NY: Simon and Schuster.

Schatzki, T. R., Knorr-Cetina, K., \& von Savigny, E. (2001). The practice turn in contemporary theory. London: Routledge.

Schmeck! (n.d.). Schmeck!. Retrieved from https://www. schmeckprojekt.de

Schneider, A., \& Ingram, H. (1990). Behavioral assumptions of policy tools. The Journal of Politics, 52(2), 510-529.

Schwarz, O. (2013). Bending forward, one step backward: On the sociology of tasting techniques. Cultural Sociology, 7(4), 415-430.

Scott, J. C. (1998). Seeing like a state: How certain schemes to improve the human condition have failed. New Haven, CT: Yale University Press.

Shapin, S. (2012). The sciences of subjectivity. Social Studies of Science, 42(2), 170-184.

Shove, E., Pantzar, M., \& Watson, M. (2012). Dynamics of social practice: Everyday life and how it changes. London: Sage.

Spackman, C. (2018). Perfumer, chemist, machine: Gas chromatography and the industrial search to "improve" flavor. The Senses and Society, 13(1), 41-59.

Stuedahl, D., \& Lowe, S. (2013). Design experiments with social media and museum content in the context of the distributed museum. Nordes, 1(5), -312 .

Sutton, D. E. (2010). Food and the senses. Annual Review of Anthropology, 39, 209-223. https://doi.org/ 10.1146/annurev.anthro.012809.104957

Teil, G., \& Hennion, A. (2004). Discovering quality or performing taste? A sociology of the amateur. In M. Harvey, A. McMeekin, \& A. Warde (Eds.), Qualities of food (pp. 19-37). Manchester: Manchester University Press.

The Boston Women's Health Book Collective. (1973). Our bodies, ourselves: A book by and for women. New York, NY: Simon and Schuster.

Tracy, S. E. (2018). Delicious molecules: Big food science, the chemosenses, and umami. The Senses and Society, 13(1), 89-107.

Ulloa, A. M. (2018). The aesthetic life of artificial flavors. 
The Senses and Society, 13(1), 60-74.

van Esterik, P. (2018). Taste, socialization and infancy. In

C. Counihan \& S. Holund (Eds.), Making taste public: Ethnographies of food and the senses (pp. 11-24). London: Bloomsbury.

Voß, J.-P., Rigamonti, N., Suarez, M., \& Watson, J. (2018). Sensing collectives: Aesthetic and political practices intertwined. Sensing Collectives. Retrieved from http://sensing-collectives.org
Warde, A. (2008). Dimensions of a social theory of taste. Journal of Cultural Economy, 1(3), 321-336.

Warde, A. (2013). What sort of practice is eating? In E. Shove \& N. Spurling (Eds.), Sustainable practices: Social theory and climate change (pp. 17-30). London: Routledge.

Wells, S. (2010). Our bodies, ourselves and the work of writing. Stanford, CA: Stanford University Press.

\section{About the Authors}

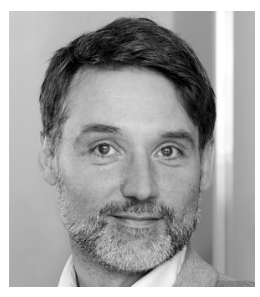

Jan-Peter Voß is Visiting Professor and Head of the Sociology of Politics and Governance Unit at Technische Universität Berlin. With a background in political science, sociology, and science and technology studies he pursues a social studies of governance approach, focusing on relations of political, epistemic, and aesthetic practices in the shaping of collective orders. Publications include Knowing Governance: The Epistemic Construction of Political Order (2016, Palgrave, edited with R. Freeman).

Michael Guggenheim is Reader at the Department of Sociology, Goldsmiths, University of London, and a Co-Director of the Centre for Invention and Social Process. His research focuses on expertise and lay people in the fields of disaster management, buildings, and cooking. He teaches inventive and visual methods and dreams of a different sociology. Most recently he has co-edited Inventing the Social (2018, Mattering Press). 